\title{
Alternative Thieno[3,2-b][1]benzothiophene Isoindigo Polymers for Solar Cell Applications
}

Marios Neophytou, Daniel Bryant, Sergei Lopatin, Hu Chen, Rawad K. Hallani, Lewis Cater, Iain McCulloch, Wan Yue*

Dr. M. Neophytou, Dr. D. Bryant, Dr. H. Chen, Dr. R. K. Hallani, L. Cater, Prof. I. McCulloch, King Abdullah University of Science and Technology (KAUST), KSC, Thuwal. 23955-6900, Saudi Arabia.

Dr. S. Lopatin, Imaging and Characterization Core Lab, King Abdullah University of Science and Technology (KAUST), Thuwal 23955-6900, Saudi Arabia.

Prof. I. McCulloch, Prof. W. Yue, Department of Chemistry and Centre for Plastic Electronics, Imperial College London, SW7 2AZ, United Kingdom.

Prof. W. Yue, Key Laboratory for Polymeric Composite and Functional Materials of Ministry of Education, School of Material and Material Engineering, Sun Yat-sen University, Guangzhou 510275, China.

Email: yuew5@mail.sysu.edu.cn

\begin{abstract}
We report the synthesis, characterization, photophysical and photovoltaic properties of five new TBTI containing low band gap donor-acceptor conjugated polymers with a series of comonomers and different side chains. When TBTI is combined with different electron-rich moieties even small structural variations can have significant impact on thin film morphology of the polymer:PCBM blends. More importantly, we used high-resolution electron energy loss spectroscopy (EELS) technique to investigate the phase separated bulk heterojunction domains, which could be accurately and precisely resolved, enabling an enhanced correlation between polymer chemical structure, photovoltaic device performance and morphology.
\end{abstract}

\section{Introduction}


Organic photovoltaics (OPVs) have seen a rapid increase in performance in recent years with efficiencies over $13 \%$ being reported. ${ }^{1}$ This resurgence in efficiency has been lead primarily through new molecular design and efficient morphological control of both donor and acceptor. ${ }^{2-11}$ The importance of morphology for high efficiency organic photovoltaics has been highlighted many times, ${ }^{11}$ an optimised interpenetrating network of the two components is needed for efficient exciton dissociation. As a result, two main strategies to control the size of the domains of each material have emerged: processing optimisation and chemical design. The former involves utilization of processing additives, thermal, solvent vapour treatments and interlayer modification, ${ }^{2,8,10}$ while the latter includes solubilizing group optimisation (linear or branched side chains) and polymer core modification. ${ }^{6}$

Isoindigo has been gaining particular interest in organic optoelectronics applications due to its simple synthesis, electron-withdrawing capability, and strong optical absorption. The easy molecular modification nature of isoindigo, through the introduction of side-groups and the interchanging of different electron-rich and electron deficient sub-units, resulted in great scientific interest over the last few years. ${ }^{12-21}$ Previously the $\pi$-conjugated, rigid and planar aromatic structure of isoindigo has been utilised as building blocks for high mobility polymers for OFETs. ${ }^{12,13,15,17,18}$ In parallel, significant progress has been achieved in OPV devices utilising donor polymers based on the isoindigo core. ${ }^{19,20,21}$ Recently we reported an isoindigo polymers containing an eight-rings fused new isoindigo core thieno[3,2-b][1]benzothiophene isoindigo (TBTI), which was solubilized with branched a 2-decyltetradecyl chain and copolymerized with thiophene. These novel low bandgap polymers allow morphological control of the bulk heterojunction through variation of molecular weight, resulting in a photovoltaic efficiency of $9.1 \%$ without the usage of any additive. ${ }^{14}$

Since the energy levels, bulk morphology and device performance were largely controlled by the alternating electron donating and electron accepting units. Therefore, regarding the 
choice of the repeat unit based on TBTI framework, different electron donating comonomer units were introduced. A small optical band gap $\left(E_{\mathrm{g}}\right)$ is typically achieved in isoindigo polymers by either increased planarization along the polymer backbone or by the inclusion of electron rich units such as thiophene or preferably with selenium derivative or the more electron rich pyrrole. Difluorination of the electron rich component of the backbone however is expected to lower the lowest unoccupied molecular orbital (LUMO) whereas the highest occupied molecular orbital (HOMO) will experience a lower electron density, but increased delocalisation due to improved planarization. The vinyl bithiophene structure can lead to a more planar backbone and enhance effective conjugated length to facilitate the intramolecular and intermolecular charge transport. When the electron deficient vinylene nitrile group is attached onto the rigid vinylene backbone, the strong electron deficient effect significantly lowers both the HOMO and LUMO energy levels of the polymers to increase the $V_{\text {oc }}$ of the solar cells. ${ }^{22}$ The nature of the side chains has an important role in the solid-state packing, aggregation and solubility of the polymers. Even the distance of branching point of the side chains to the polymer backbone can influence charge transport and OPV performance of the polymers. ${ }^{6,23,24,25,26}$ The variations of comonomer and size/shape of side chains affects polymer crystallinity, as well as affinity with PCBM, therefore influencing both polymer-PCBM interactions and domain sizes, which influences the photovoltaic parameters of the device. Traditional techniques such atomic force microscopy (AFM) which is sensitive just to surface interactions and roughness, or conventional transmission electron microscopy (TEM) strongly dependent on sample thickness and density variation, cannot characterize the domain structure unambiguously.

Herein, we report on five novel thieno-benzothiophene isoindigo (TBTI) donor-acceptor (DA) polymers with different electron donating monomers of varying oxidation potential. We report how the choice of the electron rich unit influences the optical properties, molecular 
energy levels and solar cell performance. Importantly, the impact of the chemical backbone modifications on the morphology of the blend has been studied using a method of scanning transmission electron microscopy (STEM) combined with high resolution electron energy loss spectroscopy (EELS). ${ }^{27,28}$ Using this method, the domains could be accurately and precisely resolved, enabling an enhanced correlation between polymer chemical structure, photovoltaic device performance and acquired morphology.

\section{Results and Discussion}

\subsection{Synthesis and Characterisation}

The molecular structures and synthetic route of the polymers are depicted in Scheme 1 and the Supporting Information. The synthesis of the TBTI monomer follows our previously reported methodology. ${ }^{14}$ Polymers TBTISe, TBTIFT, TBTIP, with selenophene, difluorothiophene and pyrrole as the repeat units respectively, containing branched 2-decyltetradecyl chains, have been synthesized via microwave assisted Stille polymerization in chlorobenzene, in the presence of $\mathrm{Pd}_{2}(\mathrm{dba})_{3}$ and $\mathrm{P}(o-\mathrm{Tol})_{3}$ as the catalyst system. In addition, a longer branched 3octadecylheneicosyl alkyl chain was introduced to the TBTI to guarantee sufficient solubility of the resulting polymers, when the extended coplanar structure of the vinyl bithiophene and vinylene nitrile bithiophene were incorporated into the polymer backbone. Microwave-assisted Stille polymerization using 1,1'-[(1E)-1,2-ethenediyldi-5,2-thiophenediyl]bis[1,1,1-trimethylStannane and (E)-2,3-Bis(5-(trimethylstannyl)thiophen-2-yl)acrylonitrile gave polymer TBTITT and TBTITT-CN respectively. The number average molecular weights $(\mathrm{Mn})$ of the polymers were evaluated by gel permeation chromatography (GPC) in chlorobenzene at $80{ }^{\circ} \mathrm{C}$ (Figure S1, S2, S3, S4, and S5). All the polymers exhibited relatively high Mn other than

TBTIP (Table 1), Mn and PDI are 51.5 kDa and 3.49 for TBTISe, $132.6 \mathrm{kDa}$ and 3.0 for TBTITF, $7.69 \mathrm{kDa}$ and 1.89 for TBTIP, $152.0 \mathrm{kDa}$ and 3.48 for TBTITT, and $291.6 \mathrm{kDa}$ and 
2.49 for TBTITT-CN. TBTIP has very good solubility in chloroform, chlorobenzene (CB), and dichlorobenzene (o-DCB) attributed to its low molecular weight. The other polymers have a reasonable solubility in warm $\mathrm{CB}$ and $o$-DCB. Thermogravimetric analysis (TGA) demonstrated that all polymers exhibited good thermal stability with a 5\% weight-loss decomposition temperature of $445{ }^{\circ} \mathrm{C}$ for TBTISe, $410^{\circ} \mathrm{C}$ for TBTITF, $420{ }^{\circ} \mathrm{C}$ for TBTITT, $420{ }^{\circ} \mathrm{C}$ for TBTITT-CN and $405^{\circ} \mathrm{C}$ for TBTIP (Figure S6 and S7).
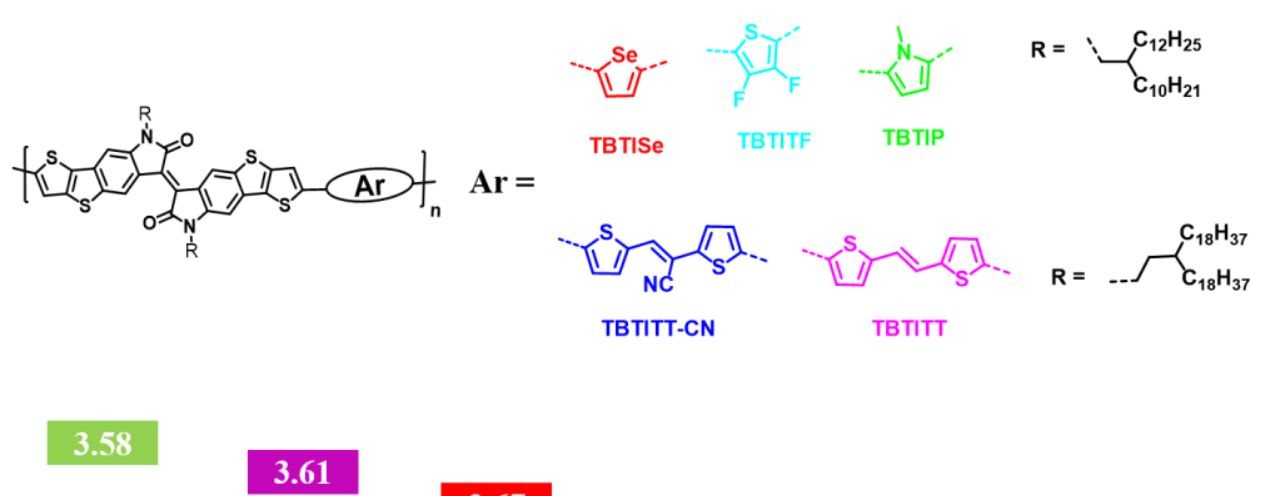

3.67

TBTIP TBTITT

\subsection{6}

TBTITT TBTISe

5.10
5.18

$$
\text { TBTIT-CN }
$$

5.15

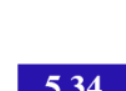

\subsection{0}

TBTIF

5.39

\section{0}

$\mathrm{PC}_{70} \mathrm{BM}$

6.1

Scheme 1: Polymer structures and energy levels of thieno[3,2-b][1]benzothiophene isoindigo polymers TBTITSe, TBTITF, TBTIP, TBTITT, TBTITT-CN and PC70BM.

Table 1. Molecular weights and optical properties and frontier molecular orbital energy levels of the polymers.

\begin{tabular}{lccccccccc}
\hline polymer & $\mathrm{Mn}^{a}$ & $\mathrm{Mw}^{a}$ & $\mathrm{PDI}^{a}$ & $E_{\mathrm{g}}{ }^{b}$ & $\mathrm{IP}^{c}$ & $\mathrm{EA}^{d}$ & $\mathrm{~T}_{\mathrm{d}}{ }^{e}$ & $\lambda_{\max (\mathrm{soln})^{f}}$ & $\lambda_{\max (\mathrm{film})^{g}}$ \\
& {$[\mathrm{kDa}]$} & {$[\mathrm{kDa}]$} & & {$[\mathrm{eV}]$} & {$[\mathrm{eV}]$} & {$[\mathrm{eV}]$} & {$\left[{ }^{\circ} \mathrm{C}\right]$} & {$[\mathrm{nm}]$} & $\begin{array}{c}{[\mathrm{nm}]} \\
\end{array}$ \\
\hline TBTISe & 51.5 & 179.7 & 3.49 & 1.48 & 5.15 & 3.67 & 445 & 670 & 665 \\
TBTITF & 132.6 & 397 & 3.00 & 1.59 & 5.39 & 3.80 & 410 & 642 & 640 \\
\hline
\end{tabular}




\begin{tabular}{cccccccccc}
\hline TBTIP & 7.7 & 14.6 & 1.89 & 1.52 & 5.10 & 3.58 & 405 & 627 & 626 \\
TBTITT & 152.0 & 529.1 & 3.48 & 1.57 & 5.18 & 3.61 & 420 & 671 & 662 \\
TBTITT-CN & 291.6 & 724.8 & 2.49 & 1.58 & 5.34 & 3.76 & 420 & 660 & 655
\end{tabular}

a) Mn, Mw, and PDI $(M w / M n)$ determined by GPC using low-D (<1.10) polystyrene standards and chlorobenzene as the eluent at $80^{\circ} \mathrm{C}$; b) Estimated from the onset of $U V-$ vis absorption spectrum (Eg $\left.=1240 / \lambda_{\text {onset }}\right)$; c) Measured by PESA; d) Estimated by the addition of $E_{g}$ to IP $(E A=I P-E g)$. e) $5 \%$ weight loss temperature measured by thermal gravimetric analysis (TGA) under a nitrogen atmosphere. f) Measured in dilute chlorobenzene solution. $g$ ) The thin films spin-cast on glass substrate from chlorobenzene solution.

\subsection{Optical Properties}

The optical absorption spectra of the polymers in dilute chlorobenzene solution and as thin films spin-cast from chlorobenzene solution are shown in Figure 1 and the data is also summarised in Table 1. All the polymers exhibit typical dual absorption bands (band I : 300$500 \mathrm{~nm}$ and band $I I$ : $500-800 \mathrm{~nm}$ ) both in solution and thin films. Band I ranging from 300 to $500 \mathrm{~nm}$ could be ascribed to the absorption of the different donor part. Absorption bands II in the low energy region was attributed to the typical charge transfer from the electron donating repeating units to the electron deficient TBTI. In solution, the TBTISe polymer exhibits the longest wavelength absorption maxima of $670 \mathrm{~nm}$ and TBTIP shows the shortest absorption maxima of $627 \mathrm{~nm}$. Upon film formation, no obvious spectral shift was observed for all polymers compared to those in dilute solution with the absorption maxima peaks are slightly blue-shifted by $1-9 \mathrm{~nm}$, suggesting some pre-aggregates in solution due to the strong intermolecular interactions of the large fused and rigid conjugated systems. Compared with the high Mn of TBTIT, ${ }^{14}$ TBTISe exhibits very similar thin film absorption spectra with high Mn 
TBTIT, showing an absorption maximum at $665 \mathrm{~nm}$ along with an obvious shoulder peak, and TBTITF shows $25 \mathrm{~nm}$ blue shifted absorption spectra, as a result of the electron-withdrawing fluorine atoms on the conjugated polymer backbone. The absorption spectra of TBTIP is also blue shifted with maximum absorption at $626 \mathrm{~nm}$ due to the weak donor ability of the pyrrole groups than that of the thiophene and selenophene. In contrast with thin film of TBTITT, which shows absorption peak at $662 \mathrm{~nm}$, the maxima of TBTITT-CN is blue shifted $7 \mathrm{~nm}$ to $655 \mathrm{~nm}$ due to the electron withdrawing nitrile groups in the polymer backbone. The asymmetry of the long wavelength absorption peaks has been attributed to coupling of vibrational modes with the electronic absorption bands. This is typically as a result of intermolecular aggregation, and thus the shoulders are a sensitive measure of short lengthscale interactions. TBTITF exhibits a pronounced absorption shoulder, suggesting that short noncovalent S-F intramolecular planarization interactions help facilitate intermolecular aggregation, whereas the rigid, planar vinyl bithiophene unit also promotes intermolecular interactions. On the other hand, the pyrrole unit seems to inhibit intermolecular interactions, and has a relatively symmetric absorption profile.

(a)

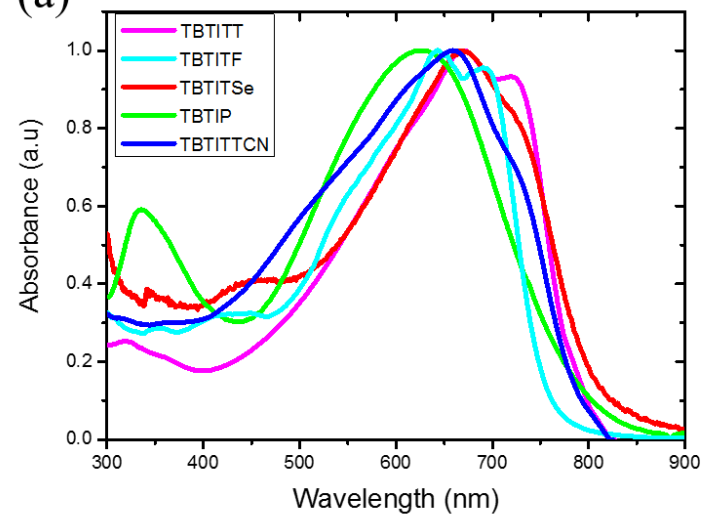

(b)

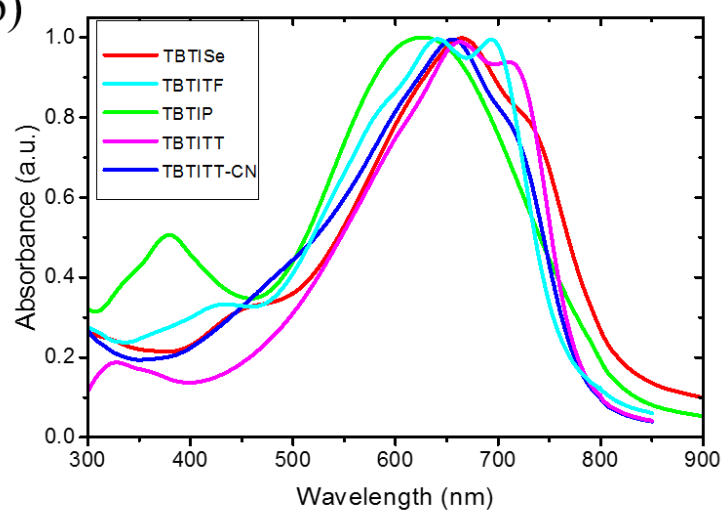

Figure 1: Normalized UV-vis absorption spectra of the polymers in dilute chlorobenzene solutions at room temperature (a) and thin films spin-cast from chlorobenzene solution (b). 
The ionization potentials (IP) of polymer thin films spin cast from chlorobenzene solution were measured using photoelectron spectroscopy in air (PESA), to be $5.15 \mathrm{eV}$ for TBTISe, $5.39 \mathrm{eV}$ for TBTIFT, $5.10 \mathrm{eV}$ for TBTIP, $5.18 \mathrm{eV}$ for TBTITT, and $5.34 \mathrm{eV}$ for TBTITT-CN. The optical band gaps of TBTISe, TBTITF, TBTIP, TBTITT, and TBTITT-CN estimated from the thin films absorption onsets are $1.48 \mathrm{eV}, 1.59 \mathrm{eV}, 1.52 \mathrm{eV}, 1.57 \mathrm{eV}$, and $1.58 \mathrm{eV}$, respectively. Interestingly, the TBTISe exhibits slightly lower $E g$ lying $1.48 \mathrm{eV}$ while the rest of the polymers show values in the range of $1.52-1.58 \mathrm{eV}$. The larger band gaps of TBTITF than that of TBTIT is consistent with the trend that fluorination on donor units reduce the HOMO energy level (increase the IP) more, resulting in larger band gap. ${ }^{18}$ The electron affinity (EA) estimated from the optical band gap to corresponding IP were found $3.67 \mathrm{eV}$ for TBTISe, $3.80 \mathrm{eV}$ for TBTIFT, $3.58 \mathrm{eV}$ for TBTIP, $3.61 \mathrm{eV}$ for TBTITT, and $3.76 \mathrm{eV}$ for TBTITTCN (Table 1). Polymers that have alternating electron rich and electron poor conjugated repeat units typically have low band gaps where the HOMO energy levels resemble to HOMO of the electron rich unit, while the LUMO resembles the electron poor unit. The higher IP and EA of both the TBTIFT and TBTITT-CN than the other four polymers can be ascribed to the strong electron withdrawing ability of the fluoro and nitrile units on the polymer backbone.

\subsection{Morphological Characterisation}

In an effort to correlate chemical structure with device performance and surface morphology, films were measured with: atomic force microscopy (AFM), scanning transmission electron microscopy (STEM) and electron energy loss spectroscopy (EELS). Polymer: PC 70 BM blends were coated on top of $\mathrm{ZnO} / \mathrm{ITO} /$ glass substrates at the optimum ratio and conditions used in solar cell fabrication. AFM images were obtained in tapping mode. STEM and EELS were performed on polymer: $\mathrm{PC}_{70} \mathrm{BM}$ blends. The films were first coated on top of a water soluble sacrificial layer and then placed on top of lacey carbon films with 300 mesh. AFM images (Figures $2 \mathrm{a}, 2 \mathrm{~d}, 2 \mathrm{~g}, 2 \mathrm{k}, 2 \mathrm{n}$ ) show that root mean square (RMS) surface roughness values for 
blends of $\mathrm{PC}_{70} \mathrm{BM}$ with polymers TBTISe, TBTIFT, TBTITT, and TBTITT-CN was around $1.65 \mathrm{~nm}$. On the other hand, TBTIP exhibited an RMS of around $2.7 \mathrm{~nm}$. In STEM image of TBTIP (Figure $2 \mathrm{~h}$ ) the extensive contrast variation is distinctly observed. This, in principle, can be attributed to phase separation and isolated domains, explaining the low current density contribution in the device EQE. In figures $2 \mathrm{~b}, 2 \mathrm{e}, 2 \mathrm{~h} 2 \mathrm{l}$ and $2 \mathrm{o}$ some contrast variation is also observed however it cannot be reliably correlated to the domains structure since it is influenced by other factors such as films thickness or density fluctuation. To analyse phase separation systematically we combined STEM with simultaneous high-resolution EELS applied to low energy region. In low energy loss region pristine polymers and $\mathrm{PC}_{70} \mathrm{BM}$ have unique EEL spectral features (or distinct signatures). In the range from 1 to $5 \mathrm{eV}$, those features result from so called inter-band transitions and have the same physical origin (related to the zone structure) as those in the UV-vis absorption spectra of polymers (Figure 1) and $\mathrm{PC}_{70} \mathrm{BM}$ (Figure $\mathrm{S} 8$ ). Tracing polymer vs $\mathrm{PC}_{70} \mathrm{BM}$ spectral signatures in spatially resolved EELS data from the composite films allows to obtain individual components maps. The component maps can be colorized (red for $\mathrm{PC}_{70} \mathrm{BM}$ and green for polymers) and then overlaid to form a single composite image. To resolve the individual spectral features reliably, the high-resolution EELS mapping was performed with strongly monochromated electron beam achieved by method first implemented by Hillenbrand et al. ${ }^{29}$ and described in details by Lopatin et al. ${ }^{30}$ Thus, the phase separation (polymer vs $\mathrm{PC}_{70} \mathrm{BM}$ ) can be accurately mapped (Figures $2 \mathrm{c}, 2 \mathrm{f}, 2 \mathrm{j}, 2 \mathrm{~m}$ and $2 p)$. This is shown most strikingly in Figure $2 \mathrm{j}$. The phase structure of the TBTIP obtained from EELS measurements is consistent with that from STEM measurements (Figure 2h), however compositional mapping shows a $\mathrm{PC}_{70} \mathrm{BM}$ phase surrounded by a TBTIP matrix. Phase segregation of this nature has previously been suggested to be from a liquid-liquid phase segregation which occurs during the drying of the films and is detrimental to device performance. ${ }^{31}$ It is noted here that various solvent mixtures were tested but no significant 
differences were observed. The variations between the morphologies of the samples of TBTITF, TBTITT-CN, TBTISe, and TBTITT are smaller and less pronounced (Figure 2c, 2f, $2 \mathrm{~m}$, and 2p). However, it is shown that of those blends: TBTITT-CN has the largest $\mathrm{PC}_{70} \mathrm{BM}$ aggregations (Figure $2 \mathrm{p}$ ) and TBTITT (Figure $2 \mathrm{~m}$ ) has a larger amount of individual domains with a more homogeneous size distribution. TBTISe and TBTITF (Figure $2 \mathrm{c}$ and $2 \mathrm{f}$ respectively) have similar $\mathrm{PC}_{70} \mathrm{BM}$ domain sizes, with TBTITF having a broader distribution in sizes. 

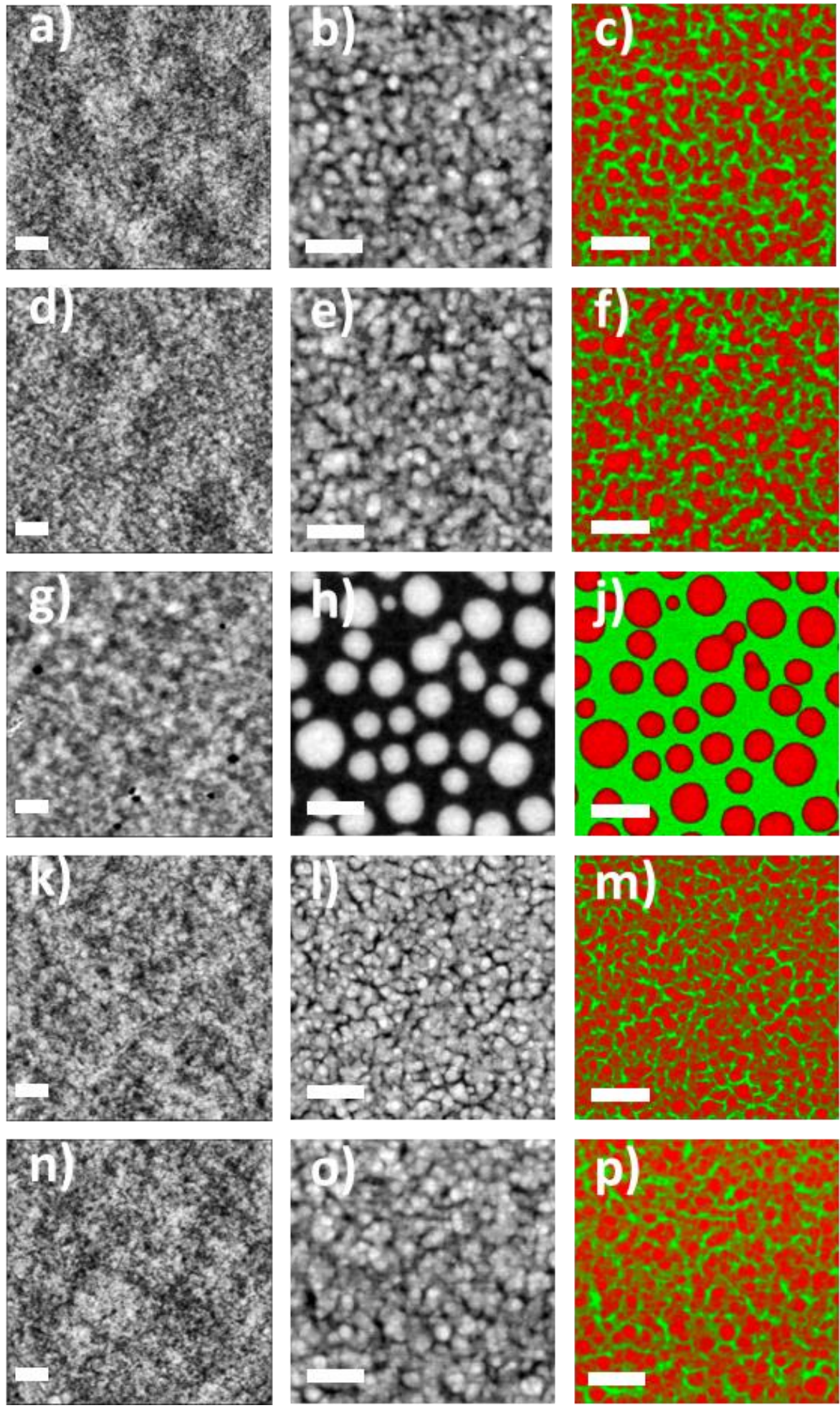

Figure 2: AFM topology (a, d, g, k, n), STEM (b, e, h, l, o) and composite EELS images (c, f, j, m, p) of TBTISe, TBTITF, TBTIP, TBTITT and TBTITT-CN. Green and red domains represent polymer and $\mathrm{PC}_{70} \mathrm{BM}$ respectively. Scale bar is $500 \mathrm{~nm}$. 


\subsection{Photovoltaic performance}

Photovoltaic devices were fabricated with an architecture of ITO/ZnO/polymer: $\mathrm{PC}_{70} \mathrm{BM} / \mathrm{MoO}_{\mathrm{x}} / \mathrm{Ag}$ and an optimised donor: acceptor weight ratio of 1:1.5 (w/w) in chlorobenzene. Current density vs applied voltage $(\mathrm{J} / \mathrm{V})$ characteristics and photovoltaic performance parameters were obtained under air mass of 1.5 Global (AM1.5G) and irradiation of $100 \mathrm{~mW} / \mathrm{cm}^{2}$ (Figure $3 \mathrm{a}$ and Table 2). Polymers TBTITF, TBTITT and TBTITT-CN show similar photogenerated current density values with selenophene based polymer (TBTISe) yielding the highest value of $11.6 \mathrm{~mA} / \mathrm{cm}^{2}$. One reason for this may be due to the higher degree of polarization and stronger intermolecular interactions caused by the Se atom. ${ }^{32}$ Despite the high photocurrent for TBTISe, champion power conversion efficiency was achieved with the bi-fluorinated-thiophene derivative, TBTITF, due to a higher $\mathrm{V}_{\mathrm{oc}}$ of $0.91 \mathrm{~V}$. Moderate efficiencies of $5.1 \%$ and $5.0 \%$ were obtained with TBTITT-CN and TBTISe respectively. Device performance seems to be unaffected by the incorporation of processing additives: 1,8diiodoctane and 1-chloro-naphthalene and/or thermal annealing both post and pre-evaporation. External quantum efficiency measurements (Figure 3b) show the onsets of the photocurrent for TBTISe and TBTITT-CN are $800 \mathrm{~nm}+/-40 \mathrm{~nm}$. For TBTITF the onset is slightly blue shifted, as expected from the wider E. In the case of TBTIP the polymer doesn't seem to contribute in the current generation (Figure 3b) as shown from the EQE. The lack of efficient polymer network that would allow charge carrier transportation and extraction could be the main reason, a statement clearly supported by TEM data. Metal-Insulator-Semiconductor charge extraction by linearly increasing voltage (MIS-CELIV) was employed in order to evaluate hole mobility at optimum active layer conditions and values are summarized at Table 2 and Figure S9. Blends of polymer: $\mathrm{PC}_{70} \mathrm{BM}$ at optimum ratios and conditions were sandwiched between a thermally evaporated insulating layer $\mathrm{MgF}_{2}(70 \mathrm{~nm})$ and $\mathrm{MoOx} / \mathrm{Ag}(6 / 100 \mathrm{~nm})$. Charge carrier mobility value for each system was extracted from the following equation: 


$$
\mu=\frac{2 d_{s}^{2}}{A t_{t r}^{2}}\left(1+\frac{\varepsilon_{s} d_{i}}{\varepsilon_{i} d_{s}}\right)
$$

Where $\varepsilon$ and $d$ are the dielectric constant and film thickness respectively of the insulator and semiconductor.
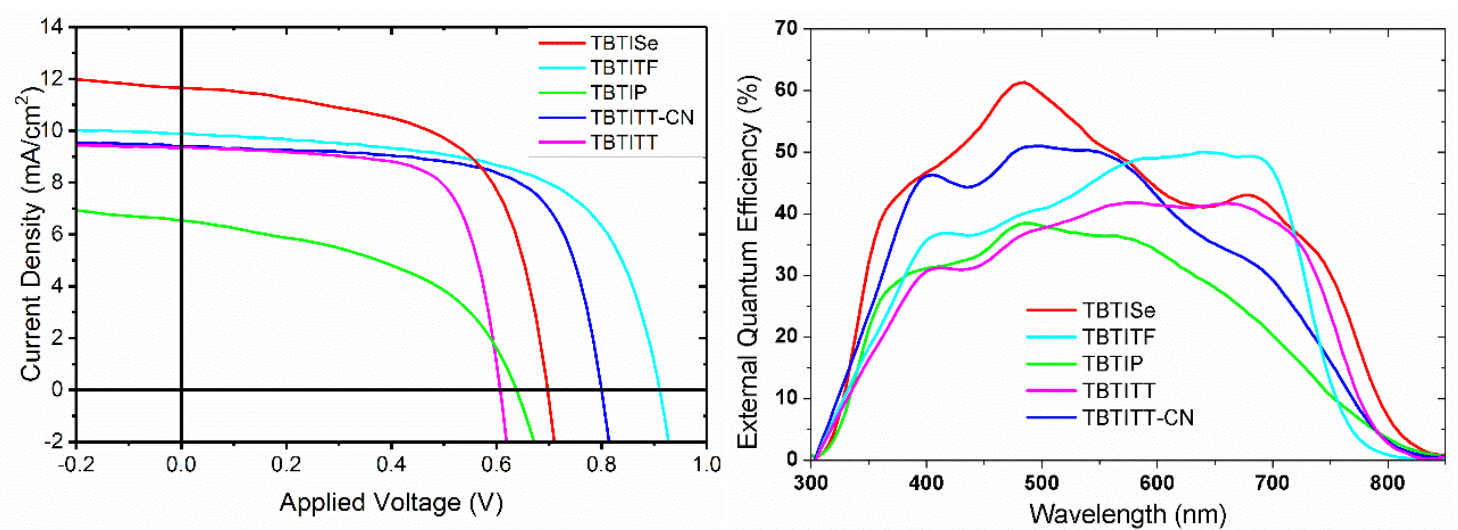

Figure 3: a) J-V characteristics and b) EQE performance characteristics of BHJ photovoltaic devices containing TBTISe, TBTITF, TBTIP, TBTITT and TBTITT-CN as the donor.

Table 2: Photovoltaic performance of BHJ photovoltaic devices utilising thieno[3,2b]benzothiophene isoindigo polymers.

\begin{tabular}{cccccc}
\hline Polymer & $J_{\mathrm{sc}}\left(\mathrm{mA} / \mathrm{cm}^{2}\right)$ & $V_{\mathrm{oc}}(\mathrm{V})$ & FF & PCE $(\%)$ & $\begin{array}{c}\mu_{\mathrm{h}} \\
\left(\mathrm{cm}^{2} / \mathrm{Vs}\right)\end{array}$ \\
\hline TBTISe & 11.6 & 0.69 & 0.61 & 5.0 & $7.4 \times 10^{-5}$ \\
TBTITF & 9.9 & 0.91 & 0.62 & 5.6 & $7.9 \times 10^{-5}$ \\
TBTIP & 6.0 & 0.67 & 0.43 & 2.0 & - \\
TBTITT & 9.4 & 0.61 & 0.70 & 4.0 & $4.1 \times 10^{-4}$ \\
TBTITT-CN & 9.4 & 0.80 & 0.68 & 5.1 & $1.1 \times 10^{-3}$ \\
\hline
\end{tabular}

It is observed that the $\mathrm{V}_{\text {oc }}$ of the photovoltaic devices follows the same trend as the IPs that the larger the IP value, the higher the $V_{\text {oc}}$. The poor photovoltaic performance of TBTIP can be attributed to the unfavourable morphology as shown by the composite EELs image in Figure $2 \mathrm{j}$. This undesirable segregation will result in a poor extraction of charges from the BHJ 
layer under illumination and can account for the poor photovoltaic performance (Table 2). All other isoindigo polymers display fill factors of 0.61-0.70 and short circuit currents of 9.4-11.6 $\mathrm{mA} / \mathrm{cm}^{2}$. This can be correlated to the high degree of mixing observed in the EELs images in Figure 2, whereby all the blend films displayed mixed BHJ structure. It is noted that the highest fill factor obtained was with the TBTITT polymer. The TBTITT showed the largest number of domains, with a homogeneously distributed smaller domain size; suggesting this morphology is preferable to achieve high fill factors, a statement also supported by MISCELIV data.

\section{Conclusions}

A series of five different thieno-benzothiophene isoindigo D/A polymers for use in photovoltaic applications were designed and synthesised. These polymers as thin films show absorption in the $300-800 \mathrm{~nm}$ region with IPs ranging $5.06-5.39 \mathrm{eV}$. When fabricated in photovoltaic devices, a highest device efficiency of $5.6 \%$ was obtained for TBTITF. The combination of STEM and high-resolution EELS imaging technique was implemented, to identify and accurately map the individual domains of polymer and PCBM - which was not possible using stand along AFM or STEM techniques. This combination of STEM and EELS mapping was used to correlate device performance to morphology; showing the lowest performing blend of TBTIP: PCBM formed a TBTIP microstructure comprising large isolated domains of PCBM. All other polymers displayed similar morphologies, reflected by their similar device performance.

\section{Supporting Information}

Supporting Information is available from the Wiley Online Library or from the author

\section{Appendix/Nomenclature/Abbreviations}




\section{Acknowledgements:}

We thank the financial support by Marie Curie Intra-European Fellowship with the 7th European Community Framework Programme (FP7-PEOPLE-2013-IEF-622187), the Young National 1000-Talents Program of China, National Natural Science Foundation of China (Grant No. 21702240), EC FP7 SC2 (610115), EC H2020 (643791) and EPSRC Project EP/G037515/1 P/M024873/1 and EP/M005143/1.

Received: Month XX, XXXX; Revised: Month XX, XXXX; Published online:

((For PPP, use "Accepted: Month XX, XXXX" instead of "Published online")); DOI: 10.1002/marc. ((insert number)) ((or ppap., mabi., macp., mame., mren., mats.))

Keywords: ((thieno-benzothiophene isoindigo, solar cells, conjugated polymers, EELS mapping))

[1]. W. Zhao, S. Li, H. Yao, S. Zhang, Y. Zhang, B. Yang, J. Hou, J. Am. Chem. Soc. 2017, $139,7148$.

[2]. J. Zhao, Y. Li, G. Yang, K. Jiang, H. Lin, H. Ade, W. Ma, H. Yan, Nat. Energy 2016, 1, 15027.

[3]. C. Duan, R. E. M. Willems, J. J. van Franeker, B. J. Bruijnaers, M. M. Wienk, R. A. J. Janssen, J. Mater. Chem. A. 2016, 4, 1855.

[4]. C. Duan, K. Gao, J. J. van Franeker, F. Liu, M. M. Wienk, R. A. J. Janssen, J. Am. Chem. Soc. 2016, 138, 10782.

[5]. C. Duan, K. Gao, F. J. M. Colberts, F. Liu, S. C. J. Meskers, M. M. Wienk, R. A. J. Janssen, Adv. Energy Mater. 2017, 7, 1700519. 
[6]. I. Meager, R. S. Ashraf, S. Mollinger, B. C. Schroeder, H. Bronstein, D. Beatrup, M. S. Vezie, T. Kirchartz, A. Salleo, J. Nelson, I. McCulloch, J. Am. Chem. Soc. 2013, 135, 11537.

[7]. J. You, L. Dou, K. Yoshimura, T. Kato, K. Ohya, T. Moriarty, K. Emery, C.-C. Chen, J, Gao, G. Li, Y. Yang, Nature Commun. 2013, 4, 1446.

[8]. A. R. b. M. Yusoff, D. Kim, H. P. Kim, F. K. Shneider, W. J. d. Silva, J. Jang, Energy Environ. Sci. 2015, 8, 303.

[9]. Y. Huang, E. J. Kramer, A. J. Heeger, G. C. Bazan, Chem. Rev. 2014, 114, 7006.

[10]. J. K. Lee, W. L. Ma, C. J. Brabec, J. Yuen, J. S. Moon, J. Y. Kim, K. Lee, G. C. Bazan, A. J. Heeger. J. Am. Chem. Soc. 2008, 130, 3619.

[11]. N. Gasparini, X. Jiao, T. Heumueller, D. Baran, G. J. Matt, S. Fladischer, E. Spiecker, H. Ade, C. J. Brabec, T. Ameri, Nature Energy 2016, 1, 16118.

[12]. I. Meager, M. Nikolka, B. C. Schroeder, C. B. Nielsen, M. Planells, H. Bronstein, J. W. Rumer, D. I. James, R. S. Ashraf, A. Sadhanala, P. Hayoz, J.-C. Flores, H. Sirringhaus, I. McCulloch, Adv. Funct. Mater. 2014, 24, 7109.

[13]. R. S. Ashraf, A. J. Kronemeijer, D. James, H. Sirringhaus, I. McCulloch, Chem. Commun. 2012, 48, 3939.

[14]. W. Yue, R. S. Ashraf, C. B. Nielsen, E. Collado-Fregoso, M. R. Niazi, S. A. Yousaf, M. Kirkus, H-Y Chen, A. Amassian, J. R. Durrant, I. McCulloch, Adv. Mater. 2015, 27, 4702.

[15]. W. Yue, M. Nikolka, M. Xiao, A. Sadhanala, C. B. Nielsen, A. J. P. White, H-Y. Chen, A. Onwubiko, H. Sirringhaus, I. McCulloch. J. Mater. Chem. C. 2016, 4, 9704.

[16]. W. Yue, C. Li, X. Tian, W. Li, M. Neophytou, H. Chen, W. Du, C. Jellett, H-Y. Chen, A. Onwubiko, I. McCulloch, J. Poly. Sci. Part A: Polym. Chem. 2017, 55, 2691. 
[17]. T. Lei, J.-H. Dou, X.-Y. Cao, J-Y. Wang, J. Pei, J. Am. Chem. Soc. 2013, 135, 12168.

[18]. Y. Gao, Y. Deng, H. Tian, J. Zhang, D. Yan, F. Wang, Adv. Mater. 2017, 29, 1606217.

[19]. J. Mei, K. R. Graham, R. Stalder, J. R. Reynolds, Org. Lett. 2010, 12, 660.

[20]. E. Wang, W. Mammo, M. R. Andersson, Adv. Mater. 2014, 26, 1801.

[21]. Y. Deng, W. Li, L. Liu, H. Tian, Z. Xie, Y. Geng, F. Wang, Energy Environ. Sci. 2015, 8,585 .

[22]. H-J. Yun, S-J. Kang, Y. Xu, S. O. Kim, Y-H. Kim, Y-Y. Noh, S-K. Kwon. Adv. Mater. 2014, 26, 7300 .

[23]. L. Fang, Y. Zhou, Y-X. Yao, Y. Diao, W-Y. Lee, A. L. Appleton, R. Allen, J. Reinspach, S. C. B. Mannsfeld, Z. Bao, Chem. Mater. 2013, 25, 4874.

[24]. I. Kang, H.-J. Yun, D. S. Chung, S.-K. Kwon, Y.-H. Kim, J. Am. Chem. Soc. 2013, 135, 14896.

[25]. Y. Zhou, T. Kurosawa, W. Ma, Y. Guo, L. Fang, K. Vandewal,Y. Diao, C. Wang, Q. Yan, J. Reinspach, J. Mei, A. L. Appleton, G. I. Koleilat, Y. Gao, S. C. B. Mannsfeld, A. Salleo, H. Ade, D. Zhao, Z. Bao, Adv. Mater. 2014, 26, 3767.

[26]. J. Mei, D. H. Kim, A. L. Ayzner, M. F. Toney, Z. Bao, J. Am. Chem. Soc. 2011, 133, 20130.

[27]. Y. Firdaus, L. P. Maffei, F. Cruciani, M. A. Müller, S. Liu, S. Lopatin, N. Wehbe, G. O. N. Ndjawa, A. Amassian, F. Laquai, P. M Beaujuge, Adv. Energy Mater. 2017, 1700834.

[28]. R.-Z. Liang, M. Babics, A. Seitkhan, K. Wang, P. B. Geraghty, S. Lopatin, F. Cruciani, Y. Firdaus, M. Caporuscio, D. J. Jones, P. M. Beaujuge, Adv. Funct. Mater. 2017, 1705464. 
[29]. A. A Govyadinov, A. Konečná, A. Chuvilin, S. Vélez, I. Dolado, A. Y Nikitin, S. Lopatin, F. Casanova, L. E Hueso, J. Aizpurua, R. Hillenbrand, Nature Commun. 2017, 8, 95.

[30]. S. Lopatin, B. Cheng, W-T. Liu, M.-L. Tsai, J-H. He, A. Chuvilin, Ultramicroscopy, 2018, 184, Part A, 109.

[31]. J. J. van Franeker, M. Turbiez, W. Li, M. M. Wienk, R. A. J. Janssen, Nat. Commun, 2015, 6229.

[32]. R. S. Ashraf, I. Meager, M. Nikolka, M. Kirkus, M. Planells, B. C. Schroeder, S. Holliday, M. Hurhangee, C. B. Nielsen, H. Sirringhaus, and I. McCulloch, J. Am. Chem. Soc. 2015, 137, 1314.

The table of contents entry should be 50-60 words long, and the first phrase should be bold. The entry should be written in the present tense and third person. The text should be different from the abstract text.

Five alternative thieno-benzothiophene isoindigo D-A polymers have been designed, synthesized and characterized, their photo physical and photovoltaic properties have been investigated. A novel composite EELS imaging technique was used to determine the domains between polymers and PCBM, enabling an enhanced correlation between polymer chemical structure, photovoltaic device performance and acquired morphology.

M. Neophytou, D. Bryant, S. Lopatin, H. Chen, R. K. Hallani, L. Cater, I. McCulloch, W. Yue*

Alternative Thieno[3,2-b][1]benzothiophene Isoindigo Polymers for Solar Cell Application 


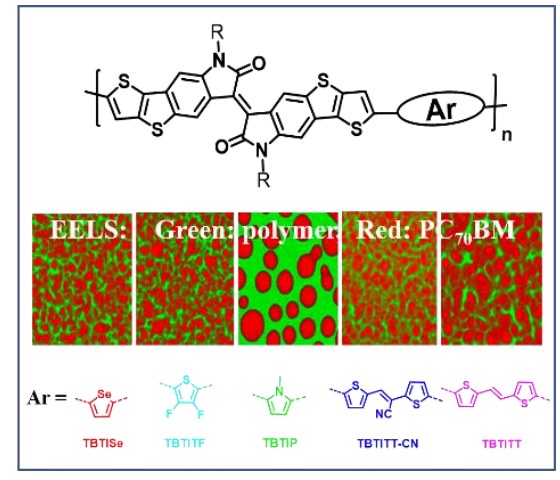

